\title{
Efforts to Overcome Homelessness in the Pruitt Branch of the Nashville Public Library
}

Olivia G. Forehand, University of Tennessee, Knoxville, USA

\begin{abstract}
In this article, the author analyzes the services and resources made available to patrons who are experiencing homelessness within the surrounding area of the Nashville Public Library's Pruitt Branch in south Nashville, Tennessee. Utilizing a framework composed of elements regarding information sources, organizational planning, and connections made with internal and external organizations, the author researched the services offered to patrons experiencing homelessness to determine any areas for improvement via the Nashville Public Library's main website. Then, a strategic action plan composed of four steps was developed for how this branch can improve its future services for the population of patrons who are experiencing poverty and/or homelessness. These four steps are to: 1) Collect patron feedback regarding what services the library is currently offering and what future changes they would like to see made. 2) Make information about the library's diversity committee more publicly accessible. 3) Prioritize meeting objectives directly related to the subject of homelessness. 4) Create more programming focused on helping patrons who are experiencing homelessness.
\end{abstract}

Keywords: diversity and inclusion; homelessness; programs; public libraries; resources and services

Publication Type: research article

\section{Introduction}

$\mathrm{T}$ he American Library Association (ALA, 2010) recognizes that people experiencing homelessness make up a large portion of public library users. Public libraries are one of the few places they can go to both seek shelter and access the information and services they need (Mars, 2013). For example, public libraries offer high-speed Internet access as an important service that is valuable to people who may have difficulties accessing such services elsewhere (Kelley, 2013). Access to computers and the Internet is becoming a requirement to stay abreast of the changes in our increasingly digital world (Kelley, 2013). Public libraries are uniquely positioned to offer more than just this invaluable access to the Internet; they offer additional assistance to people experiencing homelessness outside of answering reference questions and recommending books to read. As community referral agencies, these libraries are able to offer information about social services and additional resources to aid patrons experiencing homelessness outside the context of the library (Mars, 2013).

This article focuses on how the Pruitt Branch of the Nashville Public Library provides a variety of traditional and non-traditional services and addresses subjects related to homelessness in its community. By applying the strategic diversity manifesto (SDM) introduced by Mehra and Davis (2015) to the Pruitt Branch Library and utilizing their strategy of researching library websites to 
discover the responses to diverse communities, the Pruitt Branch's current offerings and responses to patrons who are experiencing homelessness are analyzed and a strategic action plan for how the library can improve its services to this population is proposed.

\section{The Context}

\section{Environment and Setting}

The area in which the Pruitt Branch of the Nashville Public Library is located is in south Nashville in Tennessee. It is situated near two public housing projects: the Sudekum Apartments and the J.C. Napier Homes. According to the Nashville Public Library Facilities Master Plan 2015-2040 (Nashville Public Library, 2016), the Pruitt Branch is located in what is referred to as the Central quadrant, which "contains the greatest proportion of impoverished and lower-income residents of Nashville, and many of its people suffer from the digital divide and a similar transportation divide" (p. 16). According to County Health Rankings (2017), 27\% of children in Davidson County (where the library is located) live below the poverty line. It has been found that "Childhood experiences... have a tremendous impact on future violence victimization and perpetration, and lifelong health and opportunity... Adverse Childhood Experiences (ACEs) have been linked to: risky health behaviors, chronic health conditions, low life potential, and early death" (Centers for Disease Control and Prevention, 2016, para. 1-2). Children in low-income households are likely to feel the effects of this poverty throughout the rest of their lives.

While the specific area surrounding the Pruitt Branch has its weaknesses, the city of Nashville has many strengths when it comes to helping combat the threats faced by this segment of the population. There are several local organizations whose purpose is to assist those in poverty, including Open Table Nashville and the Nashville Food Project. Open Table Nashville is a nonprofit organization that "disrupts cycles of poverty, journeys with the marginalized and provides education about issues of homelessness" (Open Table Nashville, n.d.-a). The Nashville Food Project is a nonprofit organization that "embraces a vision of vibrant community food security in which everyone in Nashville has access to the food they want and need through a just and sustainable food system" (Nashville Food Project, n.d.). There are many opportunities for growth in Nashville, specifically in the neighborhood that houses the Pruitt Branch Library. While the previously mentioned organizations do provide aid to Nashville as a whole, the residents of the neighborhood could benefit from more localized assistance.

\section{Community and User Profile}

The community of Davidson County, where Nashville is located, is more diverse than the state of Tennessee as a whole. Davidson County residents are $65.2 \%$ white, $28.1 \%$ black, and $10.1 \%$ Hispanic or Latino (U.S. Census Bureau, n.d.). The percentages of Tennesseans as a whole are 78.7\% white, $17.1 \%$ black, and 5.2\% Hispanic or Latino (U.S. Census Bureau, n.d.).

Davidson County varies from the state of Tennessee in its economic statistics as well. About $18 \%$ of people in the specific 37210 zip code, where the Pruitt Branch Library is located, live in poverty; this is higher than the rest of Davidson County, where the percentage is $15.1 \%$, and of the entire state of Tennessee, which has $15.8 \%$ of people living in poverty (U.S. Census Bureau, n.d.). According to the Claritas (2018) My Best Segments website, the largest individual segment of people who live in the 37210 zip code fall into the low household income range of less than $\$ 25,000$ US per year. 
The population of the Pruitt Branch's surrounding region in the Central quadrant is not likely to grow in the coming years, as the area is urban and already developed (Nashville Public Library, 2016, pp. 16-17). With the growth of Nashville as a whole, however, gentrification is expected to spread to South Nashville and alter the demographics of the area, which could potentially alter the programming and services that the library offers as it grows and changes with its community (p. 17).

\section{Agency Profile}

The Pruitt Branch of the Nashville Public Library contains a total of 12,210 square feet including its main area, a public computer room, small meeting rooms, and a large theater-like meeting space (Nashville Public Library, 2016, p. 10). The branch offers roughly 16 programs a month with wide-ranging topics that include fitness, crafts, languages, religion, and politics (Nashville Public Library, 2018). Patrons primarily come to this library "to get help with homework, tutoring in adult literacy, and to use the computers" and this branch relies heavily on volunteers to help in all areas and with both children and adult patrons (Nashville Public Library, n.d.-i).

The Nashville Public Library system is made up of 21 branches across Davidson County (Nashville Public Library, 2016, p. 4). The mission of the library system is to "inspire reading, advance learning, and connect our community" (Nashville Public Library, n.d.-a, para. 1) and its vision strives for "all members of our diverse community to be empowered through limitless learning opportunities to enrich their lives" (Nashville Public Library, n.d.-c, p. 1). Each branch shares this mission and vision.

The Nashville Public Library acknowledges that since each branch is located in a specific community within the Nashville area, a one-size-fits-all policy is not appropriate when serving its diverse neighborhoods and their varying needs. In the library's collection development policy, emphasis is placed on "the interests and needs of the actual and potential users of the branch" in that they "are continually evaluated so that each library has a collection reflecting the community that it serves... Branch collections are designed to serve the current, high interest needs of library patrons" (Nashville Public Library, n.d.-c, p. 2). Similarly, each branch has different services and programs that are suited to the needs of the patrons of the area in which they are located.

While the Nashville Public Library system as a whole offers many services and resources to those patrons who are experiencing poverty or homelessness, the degree to which these problems are addressed varies between the system's branches. The Main library, located on Church Street in downtown Nashville, offers the most programs and services for this population (Nashville Public Library, 2018). This is likely due to the large number of people experiencing homelessness who live across the street in the Church Street Park and make use of the library every day.

\section{Literature/Scholarship Review}

The U.S. Department of Housing and Urban Development (2017) defines the word homeless as describing "a person who lacks a fixed, regular, and adequate nighttime residence" (p. 2). A person experiencing poverty has an annual income that falls below the poverty threshold, which is adjusted each year according to inflation (U.S. Census Bureau, 2017a). In 2017, the poverty threshold for a single individual under the age of 65 years was $\$ 12,752$, for a two-person household under the age of 65 years was $\$ 16,414$, and for two people with one related child was $\$ 16,895$ (U.S. Census Bureau, 2017b). The ALA (2007) emphasizes that poverty and homelessness 
are conditions that people experience and should not become synonymous with the people themselves. The ALA (2018) uses the phrase "persons experiencing homelessness" to describe this group of patrons, so this language is mirrored throughout this report.

Through the study of relevant literature on the topic of homelessness, it was found that many public libraries tend to treat people experiencing homelessness as "problem patrons," creating policies that limit the ways of using the library that are deemed acceptable. In the article "Homelessness and the Ethics of Information Access," Bardoff (2015) explores the implications of creating library policies that single out patrons who are experiencing homelessness. These policies address behavior like loitering at the library, sleeping, washing one's body or clothes in the bathroom, or otherwise using the library in an "incorrect" way. While it has largely been found to be legal to impose such behavioral policies, Bardoff questions if it is ethical to do so, since these policies tend to unfairly target people who are experiencing homelessness. Similarly, in the article "Public Libraries and Difficulties with Targeting the Homeless," Muggleton (2013) rejects the idea that there should be a narrowly-defined acceptable way for patrons to use the library. He posits effective ways in which libraries can include people experiencing homelessness in their programs and services without oversimplifying this broad category of people and reducing individuals to negative stereotypes. Namely, the author advises library staff to make it clear to patrons who are experiencing homelessness that all of the library's resources and programs are for them, too, instead of creating homeless-specific programs, like movie nights, that unnecessarily put those patrons in a category of "other."

Pressley's (2017) article “Public Libraries, Serious Mental Illness, and Homelessness: A Survey of Public Librarians" addresses the intersections of mental illness with homelessness. While $18.1 \%$ of U.S. adults are affected by mental illness, $50 \%$ of people experiencing homelessness have a mental illness. Additionally, while only $4.2 \%$ of U.S. adults have what is considered a serious mental illness, which includes schizophrenia, bipolar disorder, and major depression, about $25 \%$ of people experiencing homelessness are affected by a serious mental illness (p. 61, p. 66). Instead of perceiving this group of people as "problem patrons," librarians should make efforts to provide the resources this group of patrons may need to move forward in their recovery. Pressley (2017) describes how creating displays and providing information about mental illness helps destigmatize the topic and creates an environment where more people with different mental illnesses are willing to ask for the information they might need (p. 73).

The literature on the subject of homelessness largely describes the need for compassion and empathy in public libraries. Services and programs should be made available to aid this population; however, care should be taken to ensure that these patrons are not divided into a solitary group, but are included and embraced in all of the library's operations.

\section{The Strategic Diversity Manifesto: A Brief Analysis}

To evaluate the Pruitt Branch's responses related to the subject of homelessness, Mehra and Davis's (2015) SDM was applied to the library's offerings. The SDM proposes a series of elements, or "what" components, that public libraries should exemplify in order to best embrace and represent the diversity within their communities. These elements are: collections and resources, information policy and planning, diversity committee and diversity representation, and internal and external connections (Mehra \& Davis, 2015, p. 21). These categories encompass any centers, organizations, departments and offices, community engagement, and news and upcoming events within the library. Mehra and Davis (2015) suggest that libraries should offer resources, programs, and services to all diverse communities that fall in the range of each of these categories and

The International Journal of Information, Diversity, \& Inclusion, 2(4), 2018

ISSN 2574-3430, publish.lib.umd.edu/IJIDI/ 
others. While providing offerings within each of these categories does not guarantee that a library is doing all it can to meet the needs of a diverse community, the SDM provides a first step to evaluating the responses of the library in regards to specific communities.

\section{Methodology}

To collect information about the Pruitt Branch Library for application of the SDM, the website of the Nashville Public Library was analyzed. Searches were performed using the website's internal search system, and Google searches were conducted pairing the term in question with "Nashville Public Library." The library's online public access catalog was used to examine the relevant information on the subject of homelessness that is included in its collections (Nashville Public Library, n.d.-b).

Observations were also made by the author, who worked at the Pruitt Branch Library as a volunteer for a number of months preceding and during the time of the research being performed in spring 2018. Additionally, feedback was gathered from staff members at the library, who will be identified through the use of pseudonyms to maintain anonymity.

To complete this analysis, only the sources, policies, connections, and responses available to patrons at the Pruitt Branch specifically were taken into account. While the Nashville Public Library system as a whole offers a variety of services to those experiencing homelessness and to diverse groups in general, fewer sources are available specifically at the Pruitt location. For example, the Main Library offers a program entitled "Coordinated Entry System Housing Help," where patrons can connect with agencies that offer housing assistance and other benefit resources; results such as these were not considered in the following analysis due to the difficulty patrons would experience attending programs at these more distant locations, despite the usefulness they might have for the patrons (Nashville Public Library, n.d.-e). There is no website specific to the library's branches, so the main site was utilized for searches.

The ALA (2012) reports that while people experiencing homelessness look for the same programs and materials as anyone else, some subjects of particular interest may include "health, mortgage or rental assistance, and applying for government benefits" (para. 4). The author paid particular attention to these subjects when examining the responses made available for the Pruitt Branch.

\section{Responses to Homelessness at the Pruitt Branch of the Nashville Public Library}

A total of six of the seven "what" component elements introduced by Mehra and Davis (2015) were found to exist at the Pruitt Branch Library. A checklist of these elements can be found in Table 1.

Table 1. Checklist of the "What" Components Available at the Pruitt Branch Library

Pruitt Branch Library

\begin{tabular}{lllllllll}
\hline & A.1 & A.2 & B.1 & B.2 & C.1 & C.2 & C.3 & Total \\
\hline Homelessness & & & X & & & & $6 / 7$ \\
\hline
\end{tabular}

Note. A.1 = Collections; A.2 = Resources; B.1 = Diversity committee; B.2 = Diversity representation; C.1 = Internal centers and organizations; C.2 = External community engagement; $C .3=$ News \& events 
Table 2. Responses Related to Homelessness in the Pruitt Branch Library

\begin{tabular}{lll}
\hline Identifier & Name & Evidence \\
\hline A. & Information sources & \\
\hline A.1 & Collections & $\begin{array}{l}\text { Items about homelessness/homeless issues are available } \\
\text { through the library catalog. }{ }^{1}\end{array}$ \\
A.2 & Resources & $\begin{array}{l}\text { Pamphlet with helpful resources can be found at the front } \\
\text { desk of the library. }\end{array}$ \\
\hline
\end{tabular}

B. Information policy and planning

$\begin{array}{lll}\text { B.1 Diversity committee } & \begin{array}{l}\text { Equity, Diversity, and Inclusion Committee exists to support } \\ \text { the Nashville Public Library's vision and values to provide } \\ \text { service to a diverse community. }\end{array}\end{array}$

B.2 Diversity representation N/A

C. Connections (Internal and external)

\begin{tabular}{lll}
\hline C.1 & $\begin{array}{l}\text { Internal centers and } \\
\text { organizations }\end{array}$ & $\begin{array}{l}\text { Link to Nashville Helps can be found on the public computer } \\
\text { start page. It is a project of the Nashville Public Library's } \\
\text { Adult Literacy program, whose goal is to connect adults to } \\
\text { the resources they need. }\end{array}$ \\
C.2 & $\begin{array}{l}\text { External community } \\
\text { engagement }\end{array}$ & $\begin{array}{l}\text { "Where to Turn in Nashville" pamphlet available at the } \\
\text { front desk; also available online. }\end{array}$ \\
C.3 & News \& events & $\begin{array}{l}\text { Free "Summer Lunch at the Library" program for children } \\
\text { and teens scheduled for July 5, 2017.4 }\end{array}$ \\
\hline
\end{tabular}

Note. ${ }^{1}$ Nashville Public Library, n.d.-b. ${ }^{2}$ Nashville Public Library, n.d.-g. ${ }^{3}$ Open Table Nashville, n.d.-b. ${ }^{4}$ Nashville Public Library, n.d.-e.

Table 2 shows the detailed findings of the "what" components regarding homelessness that are made available to patrons at the Pruitt Branch Library.

Many materials that fall under Mehra and Davis's (2015) first "what" component, collections (A.1), are available to patrons at the Pruitt Branch Library, as they are not limited only to what is physically available at the branch at the time. Any material available for checkout throughout the library system can be sent to any other branch by placing a hold on the item and specifying where the patron would like to pick the item up. This feature of the library could be better explained to patrons by staff. To find materials within the library catalog, the search terms "homeless," "homelessness," "public housing," and "food stamps," were used as examples of terms that might be used to find relevant information. System-wide, the library has holdings of 
studies done about homelessness in America, autobiographies of people who had once been homeless, and more regarding this topic (Nashville Public Library, n.d.-b).

The second element related to information sources proposed by Mehra and Davis (2015) is resources (A.2), which include databases, indexes, and research guides. Resources specifically for people who are experiencing homelessness were not found on the library's website, but through personal correspondence with one of the library staff at the Pruitt Branch. Through this source, the author learned that a pamphlet with relevant resources is made available at the front desk of the library, and is easily accessible to those who visit the library in person (A. Jones, personal communication, February 6,2018 ). This pamphlet is entitled "Where to Turn in Nashville: A Guide to Finding Help in Tennessee." This resource is discussed in more detail later, while addressing external connections.

In regards to information policy and planning, the Nashville Public Library does not include much information on its website. There is no information regarding a diversity committee specific to this branch or for the library system as a whole (B.1). However, upon discussion with an employee of the Nashville Public Library, it was discovered that there is a system-wide Equity, Diversity, and Inclusion Committee which "will examine community needs in areas related to equity, diversity, and inclusion... This committee will make recommendations for action as they relate to accessibility, hospitality, awareness, and training throughout the library system and its policies/programs" (J. Bennett, personal communication, July 20, 2018).

There are two references to the word "diversity" in a somewhat official capacity on the website (B.2). First, the webpage discussing the Nashville Public Library Facilities Master Plan (n.d.-h) makes mention of "blossoming neighborhood diversity" as being a motivating factor for the creation of the plan (para. 2). However, diversity is not mentioned within the plan itself (Nashville Public Library, 2016). Second, the collection development policy refers to diversity multiple times. This policy cites the vision of the library as: "all members of our diverse community are empowered through limitless learning opportunities to enrich their lives" (Nashville Public Library, n.d.-c, p.1). Other mentions of the words "diverse" and "diversity" are made throughout the policy, acknowledging that patrons hold diverse viewpoints and that the materials included in the library's collections must represent those diverse views (Nashville Public Library, n.d.-c).

Internal and external connections, the last set of elements suggested by Mehra and Davis (2015), include centers, organizations, departments, and offices that may be internally accessible; community engagement, such as "connections to external community-based diversity agencies"; and news and upcoming events, which includes information about programming and other events (p. 21). Regarding internal centers and organizations (C.1), the startup page that first appears when a patron accesses the Internet from one of the public computers in the library contains a link to Nashville Helps, a project of the library's adult literacy program. It is "a team of nonprofit organizations, educators, and other social service providers in the Nashville area that can help connect adults to the resources they need" (Nashville Public Library, n.d.-g, para. 1). By clicking on this link, the patron is taken to a page with information about Nashville Helps and a form that they can then fill out to select which services to which they want to be connected. There is a video included on the page with directions about how to fill out the form, and it is also mentioned that the only information required to be included in order for someone to be contacted is a phone number. Once this form is submitted, the appropriate services are contacted by Nashville Helps, who then reach out to the patron directly to provide information about how they can be of service.

The International Journal of Information, Diversity, \& Inclusion, 2(4), 2018

ISSN 2574-3430, publish.lib.umd.edu/IJIDI/ 
Regarding external community engagement (C.2), the Pruitt Branch offers pamphlets at the front desk entitled "Where to Turn in Nashville: A Guide to Finding Help in Tennessee." This resource guide is "a publication of Open Table Nashville in coordination with Middle Tennessee nonprofits" (Open Table Nashville, n.d.-b, para. 1). This guide, available in print and online, contains contact information and website links for hundreds of resources in Middle Tennessee. Some of the categories of resources include disability benefits, food stamps, mental health needs, social services, women's health, and more (Open Table Nashville, n.d.-c). The website also contains a schedule of days and locations where free meals are offered, and a list of helpful phone numbers like the Nashville police non-emergency line, Nashville Mobile Crisis, and the National Sexual Assault Hotline.

It was difficult to find a full range of news and upcoming events (C.3) that relate to homelessness on the Nashville Public Library website, since only five months of the calendar are available to be viewed (Nashville Public Library, n.d.-e). At the time of conducting this research on March 30,2018 , no future events regarding poverty or homelessness were on the calendar of the Pruitt Branch. However, upon examination of past events, a free "Summer Lunch at the Library" program for children and teens was scheduled on July 5, 2017. This program would be beneficial to those experiencing homelessness whose children rely on free lunches during the school year, and who may go without lunch when not at school (Nashville Public Library, n.d.-e).

The mission of the Nashville Public Library includes the idea of connecting the community, which can be interpreted as connecting people to the resources and information they need (Nashville Public Library, n.d.-a). It can be concluded that the Pruitt Branch is making select efforts to accomplish this mission by offering many resources to people who are experiencing homelessness. Additional steps that can be taken to further this mission and meet the expectations of people experiencing homelessness are discussed in the next section.

\section{Moving Forward (Strategic Action Plan)}

Based on the findings presented in this case assessment, it is the author's opinion that there are four steps that can improve the Pruitt Branch's responses related to homelessness. These actions take into account the data gathered from the Nashville Public Library's website, feedback from staff members, and the observations made by the author.

1. Population Needs Assessment: First, it will be beneficial for the staff at the Pruitt Branch to reevaluate the needs of the community they serve. One step is to gather feedback from the library patrons themselves about what services the library is currently offering and what future changes they would like to be made. This feedback will inform the next steps to be taken at the library regarding what programs and services need to be implemented. The feedback will also be beneficial if staff must reallocate funds or address administration to ask for a larger budget (New Mexico State Library, n.d.).

2. Mission/Vision: The author, as a volunteer for two years at this branch and at others in the library system, was never aware of any committee focused on diversity in the library. Additionally, much searching through the Nashville Public Library website did not reveal the existence of such a committee; only through conversation with an employee of the Nashville Public Library was mention made of NPL's Equity, Diversity, and Inclusion Committee. The Pruitt Branch, and the Nashville Public Library system as a whole, would benefit from including information about the library's diversity committee on the agency's website. The Nashville Public Library is making strides to serve diverse 
populations more fully, so making information about these efforts more publicly accessible would help make it clear to people experiencing homelessness that the library is for them as well.

3. Objectives: The ALA Policy Manual (2010) has a section entitled "Library Services to the Poor," which includes a list of fifteen objectives that should be implemented in order to most effectively serve this segment of the community. It is the author's opinion that the Pruitt Branch, and the Nashville Public Library as a whole, should prioritize meeting more, if not all, of these objectives. Some, like Number 5: "Promoting the incorporation of low-income programs and services into regular library budgets in all types of libraries, rather than the tendency to support these projects solely with 'soft money' like private or federal grants" and Number 6: "Promoting equity in funding adequate library services for poor people in terms of materials, facilities, and equipment" should be feasible for the Pruitt Branch to adopt (ALA, 2010). The Pruitt Branch offers many educational programs, like classes on political systems and world religions (Nashville Public Library, 2018). It is advisable for the library to reallocate some of the resources for these classes into regular programming to address the needs of people experiencing poverty and homelessness.

4. Activities: Taking into account both the feedback from Pruitt staff and the observations of the author, it is also recommended that the Pruitt Branch create more programming focused on helping patrons who are experiencing poverty or homelessness. Authorial observation has shown that basic computer classes would be beneficial to this group, because many patrons of the Pruitt Branch Library need assistance with computer tasks such as creating documents in Microsoft Word and printing. These basic computer skills would provide the foundation for more advanced workforce development classes that the library is lacking, like classes or workshops assisting patrons with job searching and resume writing. Through correspondence with A. Jones, a staff member at the Pruitt Branch Library, the author also determined that the patrons of this library will benefit from programs related to money management, health and wellness, and child care (personal communication, March 17, 2018).

\section{Conclusion (Projections)}

Poverty is an ongoing issue in the U.S.; since 1964 the number of people experiencing poverty has fluctuated between 11\% and 15\% (University of California Davis Center for Poverty Research, 2017). In Nashville, 70\% of low-income renters are cost-burdened, meaning they pay more than $30 \%$ of their income on housing (Nashville Mayor's Office, 2017). The number of patrons experiencing homelessness who seek services from the Nashville Public Library, and the Pruitt Branch specifically, do not appear to be diminishing; being physically situated near two public housing projects also ensures that many of the patrons of this branch will be experiencing these problems for the foreseeable future. It is important, then, that the Pruitt Branch is prepared to meet the needs of these patrons.

By applying the SDM created by Mehra and Davis (2015), the author has identified a number of areas for improvement in the offerings made by the Pruitt Branch of the Nashville Public Library relating to homelessness. It is the author's belief that it is feasible for the Pruitt Branch to take the steps discussed in the article, and that by doing so the Pruitt Branch will reduce gaps and strengthen its weaknesses in meeting the needs of people experiencing homelessness.

The International Journal of Information, Diversity, \& Inclusion, 2(4), 2018

ISSN 2574-3430, publish.lib.umd.edu/IJIDI/ 
Even small changes can improve the lives of patrons; in July 2017, the Nashville Public Library system stopped charging fines for overdue items in order to ensure the accessibility of their collections for all patrons (Nashville Public Library, n.d.-f). By continuing to implement similar policies, the library system will take important steps towards promoting equal access to library services for all patrons, including people experiencing homelessness.

\section{Acknowledgements}

The author thanks Dr. Keren Dali for the opportunity of this article's publication, the Editorial Team at The International Journal of Information, Diversity \& Inclusion (IJIDI) for their assistance with revising the manuscript, and Jessica Martin for her help with editing the manuscript.

\section{References}

American Library Association. (2007). Outreach resources for services to poor and homeless people. Retrieved from http://www.ala.org/advocacy/diversity/outreachtounderservedpopulations/servicespo or

American Library Association. (2010). B.8.10 Library services to the poor (Old number 61). In ALA Policy Manual. Retrieved from http://www.ala.org/aboutala/b8-services-andresponsibilities-libraries-old-number-52\#B8.10

American Library Association. (2012). Extending our reach: Reducing homelessness through library engagement. Retrieved from http://www.ala.org/aboutala/offices/extendingour-reach-reducing-homelessness-through-library-engagement-3

American Library Association. (2018). Resources for public libraries serving persons experiencing homelessness. Retrieved from http://www.ala.org/pla/resources/tools/homelessness

Bardoff, C. (2015). Homelessness and the ethics of information access. Serials Librarian, 69(3/4), 347-360.

Centers for Disease Control and Prevention. (2016). About adverse childhood experiences. Retrieved from https://www.cdc.gov/violenceprevention/acestudy/about_ace.html

Claritas. (2018). Claritas pop-facts demographics table for 37210. Retrieved from https://segmentationsolutions.nielsen.com/mybestsegments/Default.jsp?ID=20\&menu Option=ziplookup\&pageName=ZIP\%2BCode\%2BLookup

County Health Rankings. (2017). Davidson (DA). Retrieved from http://www.countyhealthrankings.org/app/tennessee/2017/rankings/davidson/county loutcomes/overall/snapshot

Kelley, P. (2013). Global study stresses importance of public Internet access. UW News. Retrieved from http://www.washington.edu/news/2013/07/10/global-study-stressesimportance-of-public-internet-access/ 
Mars, A. (2013, April 26). Library service to the homeless. Public Libraries Online. Retrieved from http://publiclibrariesonline.org/2013/04/library-service-to-the-homeless/

Mehra, B., \& Davis, R. (2015). A strategic diversity manifesto for public libraries in the 21st century. New Library World, 116(1/2), 15-36.

Muggleton, T. H. (2013). Public libraries and difficulties with targeting the homeless. Library Review, 62(1/2), 7-18.

Nashville Food Project. (n.d.). Vision, mission, \& values. Retrieved from https: / / www.thenashvillefoodproject.org/vision-mission-values/

Nashville Mayor's Office. (2017). Housing Nashville: Nashville \& Davidson County's housing report. Retrieved from https: / / www.nashville.gov/Portals/0/SiteContent/MayorsOffice/AffordableHousing/Ho using\%20Nashville\%20FINAL.pdf

Nashville Public Library. (2016). Nashville Public Library facilities master plan 2015-2040. Retrieved from https://library.nashville.org/sites/default/files/field/page/file/nplfacilities-master-plan-dec2016.pdf

Nashville Public Library. (2018). Events calendar. Retrieved from https: / / events.library.nashville.org

Nashville Public Library. (n.d.-a). About. Retrieved from https://library.nashville.org/about

Nashville Public Library. (n.d.-b). Catalog. Retrieved from https: / / catalog.library.nashville.org/

Nashville Public Library. (n.d.-c). Collection development policies. Retrieved from https: / /library.nashville.org/sites/default/files/field/page/file/nashville-publiclibrary-collection-development-policy-march2018.pdf

Nashville Public Library. (n.d.-f). FAQs about overdue fine elimination. Retrieved from https: / / library.nashville.org/faqs-about-overdue-fine-elimination

Nashville Public Library. (n.d.-g). Nashville helps. Retrieved from https://docs.google.com/forms/d/e/1FAlpQLSehjfwfQpaQL9NBSDDz30akwZ5ovmtDnEQs0_2gh_oBlajAQ/viewform

Nashville Public Library. (n.d.-h). NPL facilities master plan. Retrieved from https://library.nashville.org/npl-facilities-master-plan

Nashville Public Library. (n.d.-i). Pruitt Branch. Retrieved from https: / / library.nashville.org/locations/pruitt-branch

New Mexico State Library. (n.d.). Questionnaires and surveys. Retrieved from http://www.nmstatelibrary.org/index.php?option=com_content\&view=article\&tid=206\& Itemid=104

Open Table Nashville. (n.d.-a). Story. Retrieved from http://opentablenashville.org/story 
Open Table Nashville. (n.d.-b). Where to turn in Nashville: A guide to finding help in Middle Tennessee. Retrieved from http://www.wttin.org/

Open Table Nashville. (n.d.-c). Where to turn in Nashville: Resources. Retrieved from http://www.wttin.org/resources\#

Pressley, T. (2017). Public libraries, serious mental illness, and homelessness: A survey of public librarians. Public Library Quarterly, 36(1), 61-76.

U.S. Census Bureau. (2017a). How the Census Bureau measures poverty. Retrieved from https: //www.census.gov/topics/income-poverty/poverty/guidance/povertymeasures.html

U.S. Census Bureau. (2017b). Poverty thresholds for 2017 by size of family and number of related children under 18 years. Retrieved from https://www2.census.gov/programssurveys/cps/tables/time-series/historical-poverty-thresholds/thresh17.xls

U.S. Census Bureau. (n.d.). Quick Facts: Davidson County, Tennessee; Nashville-Davidson (balance), Tennessee; Tennessee. Retrieved from https://www.census.gov/quickfacts/fact/table/davidsoncountytennessee, nashvilledavi dsonbalancetennessee, TN/PST045217

U.S. Department of Housing and Urban Development. (2017). The 2017 annual homeless assessment report (AHAR) to Congress. Retrieved from https://www.hudexchange.info/resources/documents/2017-AHAR-Part-1.pdf

University of California Davis Center for Poverty Research. (2017). What is the current poverty rate in the United States? Retrieved from https: //poverty.ucdavis.edu/faq/whatcurrent-poverty-rate-united-states

Olivia G. Forehand (oforehan@vols.utk.edu) is a Master's student of Information Sciences at the University of Tennessee, Knoxville with a background in English. She is interested in a career in public libraries, particularly working with teens, where she hopes to incorporate inclusion and representation of diverse groups of people in her work. 